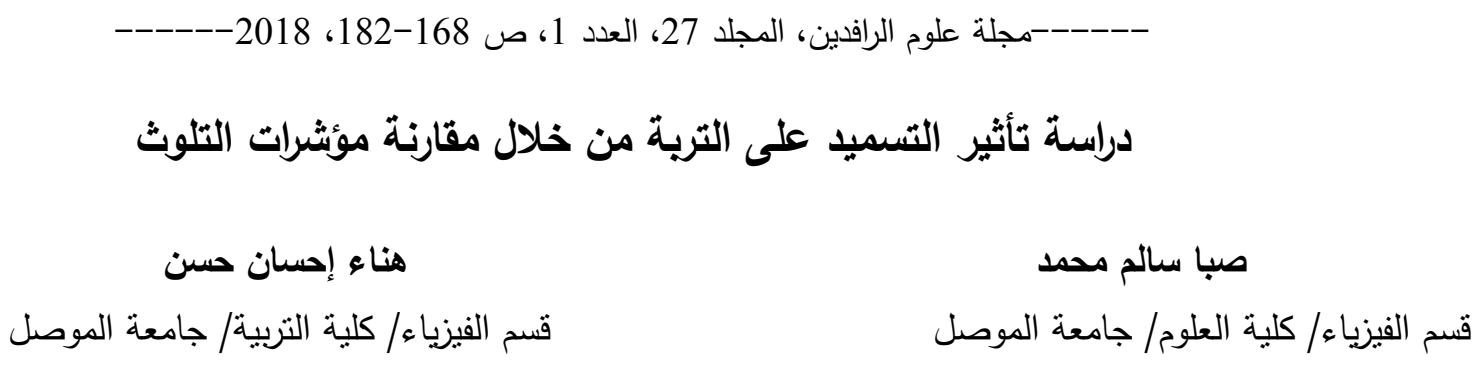

$$
\text { (أستلم 2013/ } 11 \text { (2013/12/ }
$$

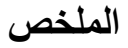

يهدف البحث الحالي الى مقارنة بعض مؤشرات التلوث الإشعاعي المنضمنة الجرعة الممنصة (D) ومكافئ الراديوم (Raeq) ومستوى التعرض الداخلي (Hin) والخارجي (Hex ) ودليل كاما ( I ) في خمس عينات من التربة المسمدة مع أخرى غير مسمدة بخمسة انواع من الأسمدة العراقية المنثأ لغرض بيان تأثير التسميد على مقدار ما يسببه من زيادة التلوث الإثعاعي، اذ تم قياس

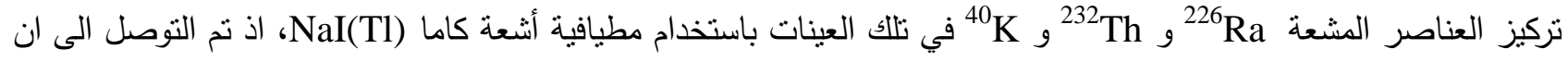
138.56 Bq/kg قيم مؤشرات الخطورة بدءاً بمعدل الجرعة المنصة و 319.31 ودليل كاما 0.987 و 2.23 والخطر الداخلي 0.488 و و1.326 والخطر الخارجي 0.374 و 0.36 و 0.862 للتربة غير

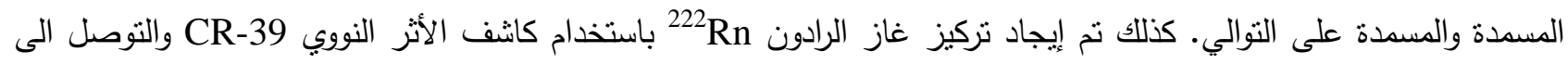

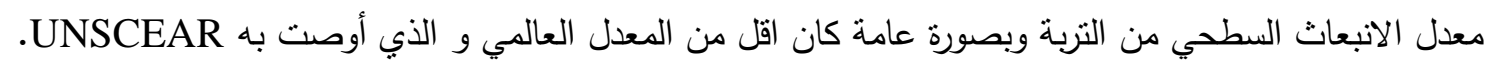

\title{
Studying the Effect of Fertilized Soil by Comparing of some Indicators of Radioactive Contamination
}

\section{Saba S. Mohammed \\ Department of Physics/College of Sciencel \\ University of Mosul}

\author{
Hana I. Hasan \\ Department of Physics/College of Education/ \\ University of Mosul
}

\begin{abstract}
The current research aims to compare some of the indicators of radioactive contamination, contained, absorbed dose (D), radium equivalent, $\left(\mathrm{Ra}_{\mathrm{eq}}\right)$, index of external and internal radiation hazard, $\left(\mathrm{H}_{\mathrm{ex}}, \mathrm{H}_{\mathrm{in}}\right)$, and gamma activity concentration index, $\left(\mathrm{I}_{\gamma}\right)$, in five soil samples unfertilized and other five fertilized with Iraqi origin fertilizers, to find the effect of fertilization on how much increases the radioactive contamination, the concentration of radioactive elements ${ }^{226} \mathrm{Ra},{ }^{232} \mathrm{Th}$ and ${ }^{40} \mathrm{~K}$ in these samples estimated by using gamma ray system $\mathrm{NaI}(\mathrm{Tl})$. It has been reached that the values of indicators of the fertilized and unfertilized soil that the rate of absorbed dose $0.0819 \mu \mathrm{Sv} / \mathrm{h}$ and $0.133 \mu \mathrm{Sv} / \mathrm{h}$, radium equivalent $138.56 \mathrm{~Bq} / \mathrm{kg}$ and $319.31 \mathrm{~Bq} / \mathrm{kg}$, gamma activity concentration index, ( $\mathrm{I} \gamma$ ) 0.987 and 2.23, the internal radiation hazard index 0.488 and 1.326, the external radiation hazard index 0.374 and 0.862 ,respectively. The surface exaltation rate of ${ }^{222} \mathrm{Rn}$ was estimated after finding the radon concentration by using nuclear track detector CR-39, the emission from the soil surface in general was less than the recommended value by UNSCEAR.
\end{abstract}




\section{المقدمة}

تعد التربة أحد أهم عناصر البيئة التي تمد الإنسان بمصادر الغذاء ولأنها وسط ديناميكي فعندما تتلوث تصبح مصدر طويل الأمد للتلوث البيئي المؤدي إلى تلوث الغذاء والماء والهواء. تتنتر العناصر الإشعاعية الطبيعية بشكل واسـع في البيئة وتعتبر المصدر الرئيسي لتعرض الإنسان للإنشعاعات المؤينة ويضاف إلى ذلك التعرض الإشعاعي الناتج عن الأنشطة الإنسانية والتي

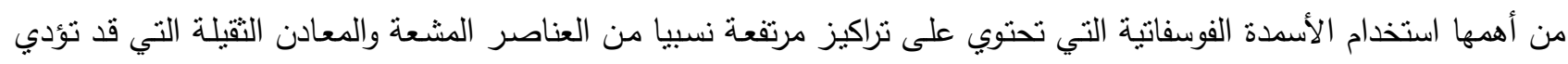
إلى ارتفاع تراكيز العناصر المشعة بالتربة والبيئة المحيطة (Al-Saif, 2009). ويعتمد النشاط الإتشعاعي في التربة على النشاط

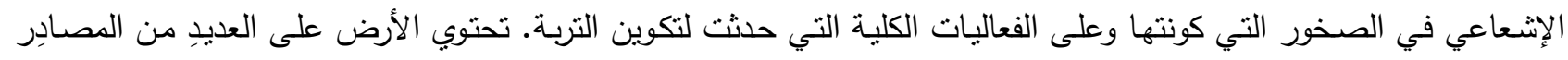

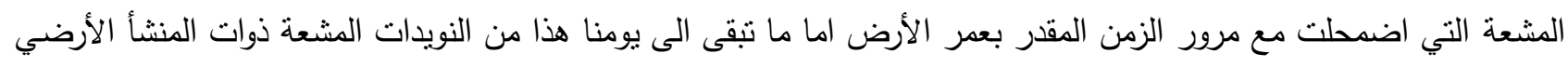

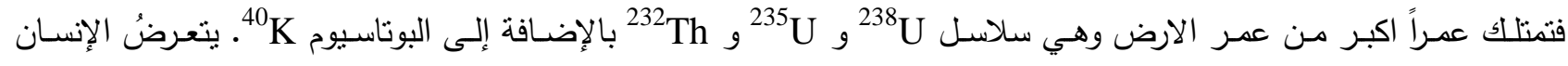

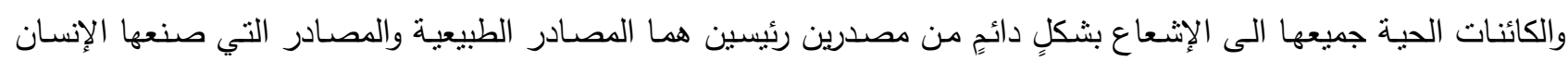

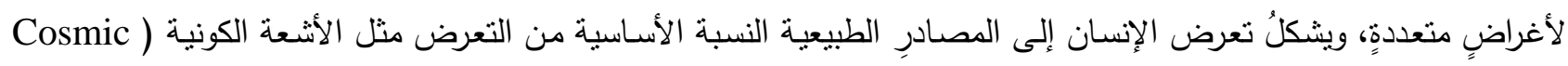

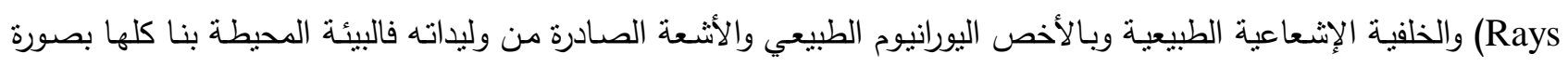
عامة تحتوي على نسبة ضئيلة من المواد المشعة (Guimond and Hardin, 1989). يعتمدُ تلوثِ التربـةِ على المعلوماتِ المتعلقة بعطياتِ الانتقالِ والتراكم بعيداً عن موقع التلوث، إذ أن حركة المواد المشعة وتراكمها أو انتقالها يعتمدُ على تفاعل المواد

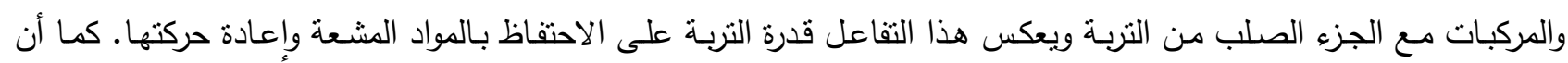
الخصائص الفيزيائية والكيميائية والحيوية للجزء الصلب من التربة تحدد قدرتها على الاحتفاظ بالمواد المشعة ومن جانب آخر فأنَّ

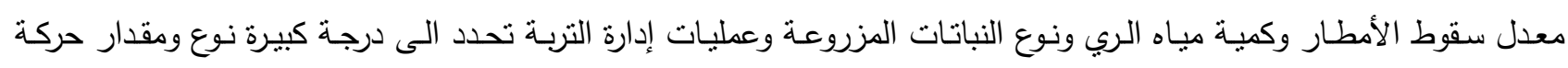
الملوثات المشعّة (سلامة ومحمد، 1994).

الأسمدة

هي عبارة عن أملاح لا عضوية تتحل في المـاء تضاف إلى التربـة الزراعية للحصول على محصول أوفر وأجود وتعود التصد

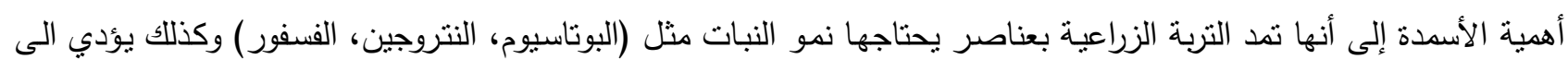

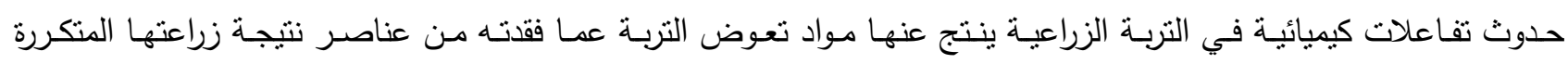

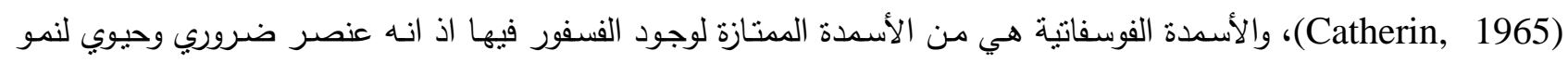
وتكاثر النبات ويعتبر اليورانيوم من العناصر ذات النشاط الإشعاعي الطبيعي الذي يتواجد في التربة ومناجم الصخور الفوسفاتية

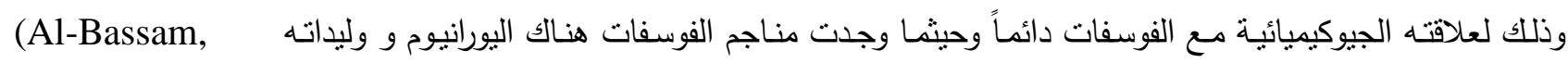
(2007 أجريت العديد من الدراسات لقياس نراكيز العناصر المشعة الموجودة في التربة المسمدة وغير المسمدة وكذللك مكافئ الراديوم والتعرض الخارجي والداخلي. وهنالك دراسات حول ثراكيز العناصر المشعة في الأسمدة ومنها دراسة قام بهات الصنة (الصبحة،

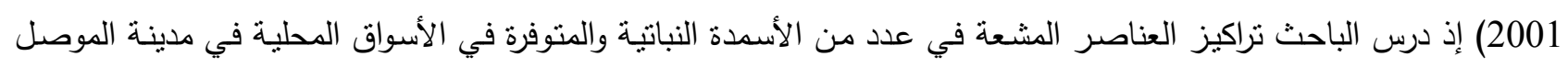

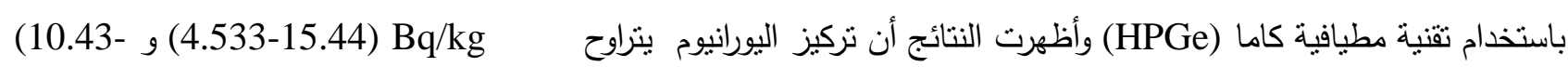

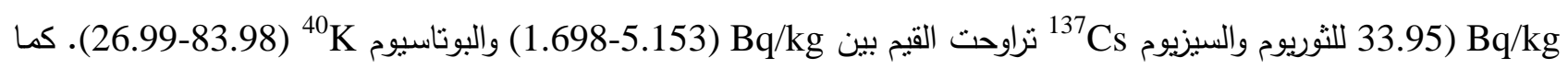
درس (Chauhan et al., 2013) تراكيز العناصر المشعة Ra وسماد NPK وكانت نتائجه لكل Ra

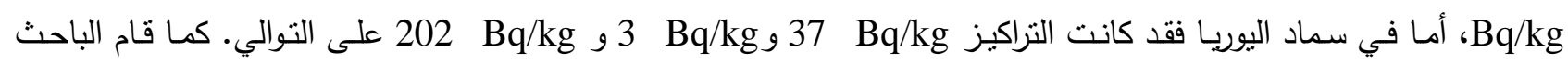
(Akhtar et al., 2005) والبايولوجيـة لقياس تركيز العناصـر المشعة في التربـة القاحلة والزراعيـة (المسمدة) وعلى مسـاحة 100 هكتار باستعمال تقنيـة 


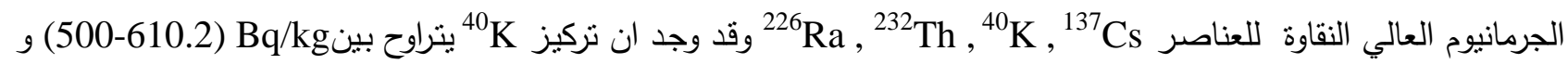

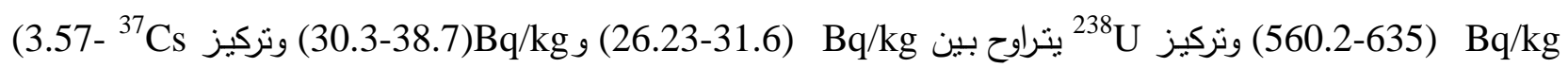

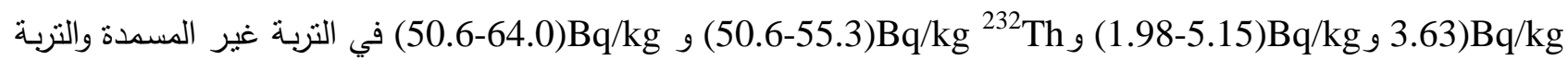
المسمدة على التوالي. وتتشير الدراسة في هذه المنطقة إلى الخلفية الاشعاعية العالية مقارنة بالعالم وهذه الزيادة ناتجة عن استعمال

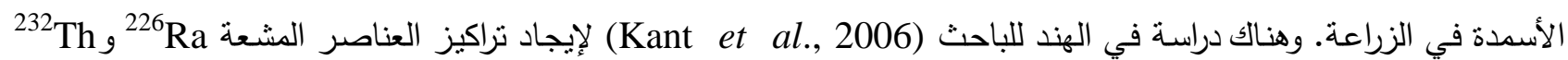
و

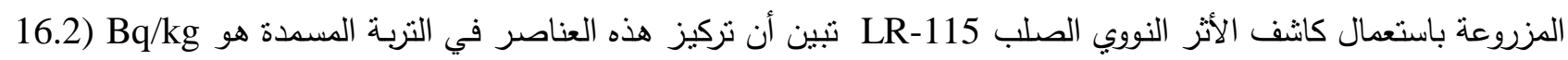

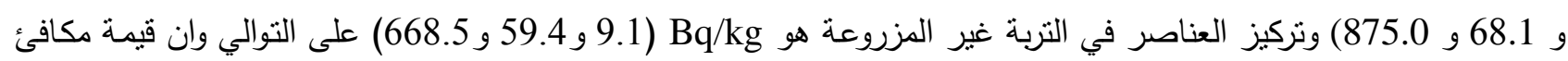

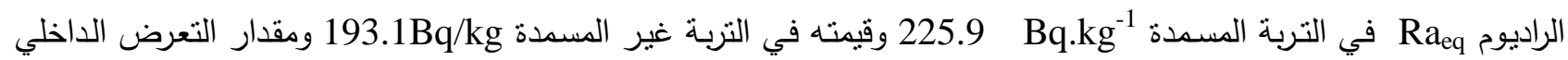

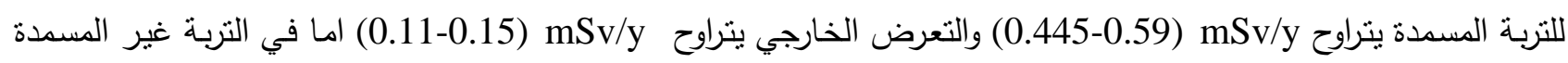
فالتعرض الخارجي/ mSv/y 0.45 والتعرض الداخلي 0.11 وتوضح نتائج هذا البحث ان تراكيز العناصر المشعة اعلاه تختلف باختلاف نوع التربة المزروعة وهذا بدوره يعتمد على كمية ونوع الأسمدة المستخدمة. كما درس (Al-Saif, 2009) تراكيز العناصـر المشـعة Ra

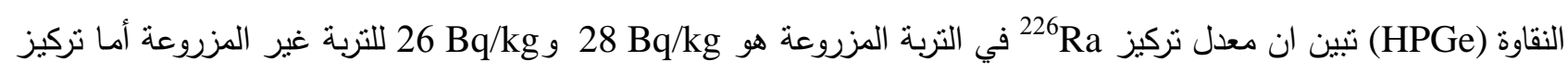

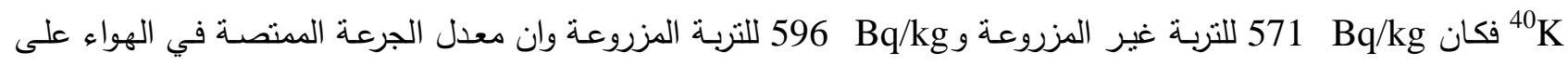

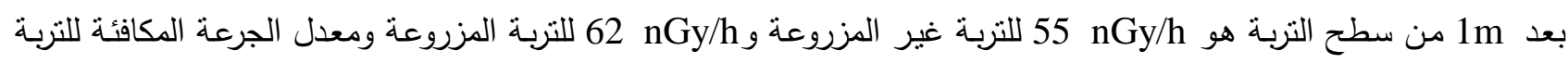

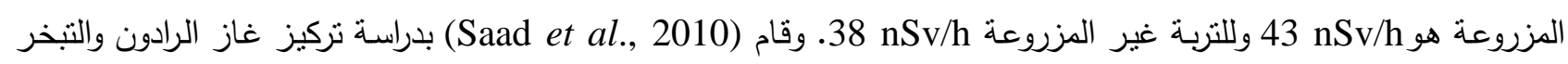
السطحي والجرعة الركافئة السنوية لـ 45 عينة من مواد البناء وباستخدام كاشف الأثر النووي الصلب CR-39 فقد تنبين تركيز غاز

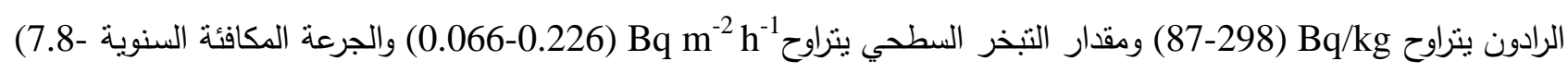

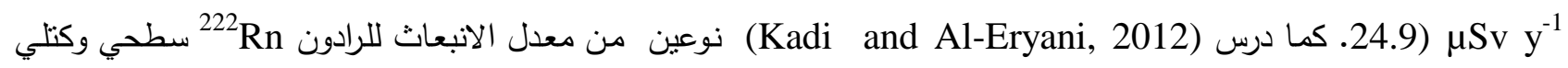

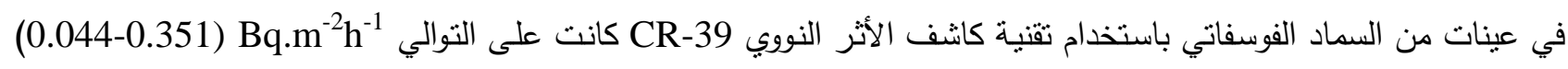
(0.023-0.180)Bq.kg ${ }^{-1} \mathrm{~h}^{-1}$,

\section{الجزء العطلي}

تقنية مطيافية أشعة كاما

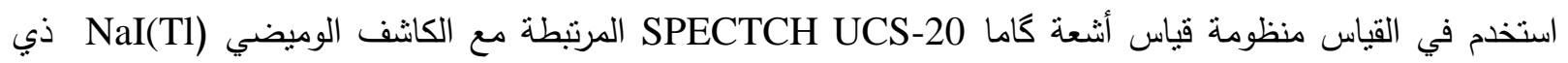
الأبعاد $2.5 \mathrm{~cm} \times 3.8 \mathrm{~cm}$ كإحدى التقنيات المختبرية وتتكون هذه المنظومة من مضخم ابتدائي ومضخم رئيس ومجهز للفولتية ومحلل متعدد القنوات وترتبط هذه المنظومة بجهاز حاسوب لغرض تتغيلها وقراءة قياساتها وتحليل النتائج، إذ نم جمع خمس عينات وبواقع كيلو غرام واحد من كل موقع من مساحة تقدر بحوالي دونم واحد من أراضي زراعية غير مسمدة ومن مواقع مختلفة

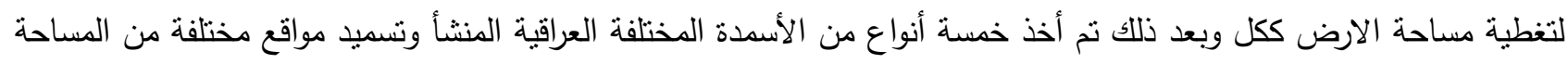

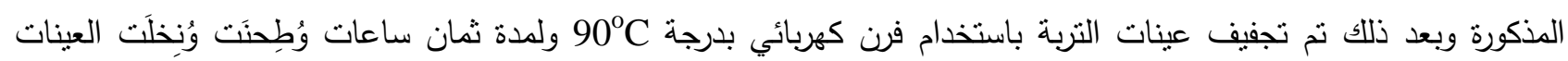
بمنخل ناعم قطره 2mm ثم خلطت بصورة جيدة للحصول على أفضل تجانس. وضعت عينات التربة المراد قياسها في وعاء مارنيللي من البلاستاك حجمه تقريبا (250 cm³

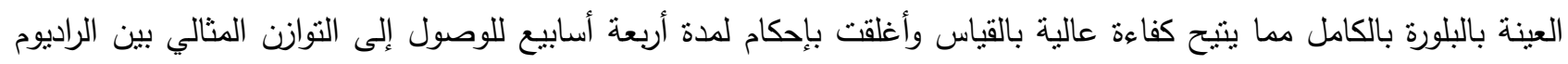
Ra 
تم معايرة المنظومة للطاقة وذلك باستخدام المصادر المشعة القياسية بطاقة )

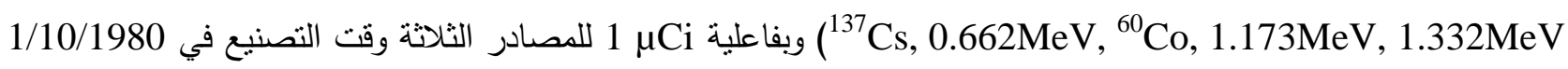
تم إيجاد كفاءة الكاشف الوميضي للطاقات $1460 \mathrm{keV} 2615 \mathrm{keV}$

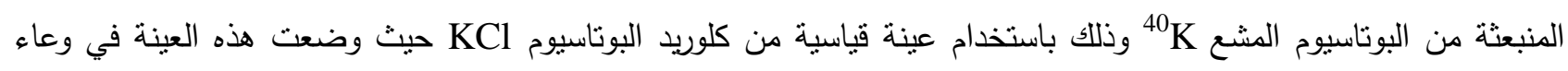
مارنيللي وحددت نسبة البوتاسيوم الطبيعي K ومن ثم البوتاسيوم المشع Kن Kن في العينة القياسية وحسبت الكفاءة لهذه الطاقة، ونم

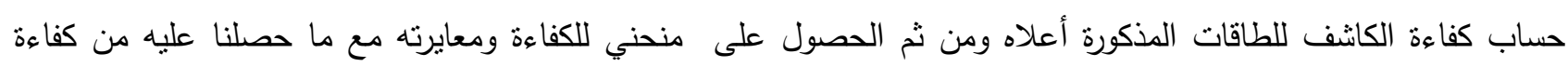

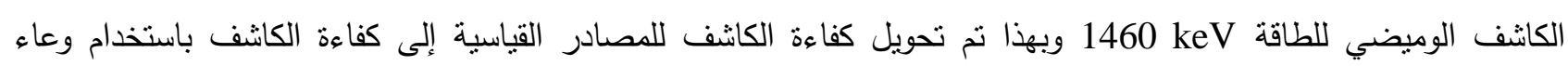
مارنيللي لكل الطاقات التي اعتمدناها في الحساب (علي وآخرون،2013).

تقتية كاشف الأثر النووي (CR-39)

استخدمنا في هذه التقنية كانشف الأثر النووي الصلب CR-39 معتمدين طريقة القياس طويلة الأمد من اجل تسجيل آثار

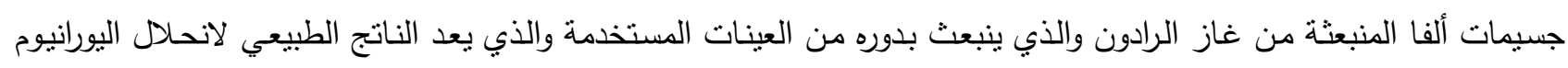

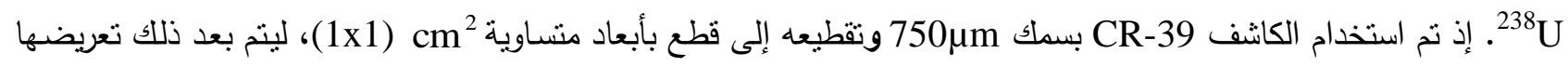
إلى العينات قيد الدراسة بعد ان تم تجفيفها وطحنها ونخلها وكما سبق ذكره في التقنية الاولى وتم اخذ 5 غرامات من كل عينة. وضعت العينات في حجرات التشعيع والتي هي عبارة عن أنابيب اختبار أسطوانية الثكل تعرف بحجرات الانتشار ذات فطر 2.2 وأغلقت تللك الحجرات بإحكام بسدادات مطاطية مع مراعاة كون المسافة بين سطح العينة وسطح السداد السفلي المثبت فيه قطعة الكاشف مساوية الى و 9.5 لجميع العينات، ثم تركت العينات لمدة 28 يوما وذللك للوصول إلى بـ $98 \%$ من حالة التوازن المثالي (القرني) بين الراديوم ووليداته من نظائر الرادون، وبعد انتهاء زمن النوازن رفعت السدادات بسرعة واستبدلت بأخرى مثبت بأسفلها قطعة الكاشف

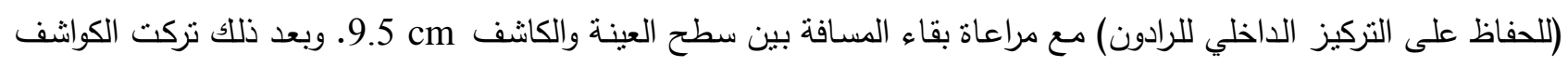

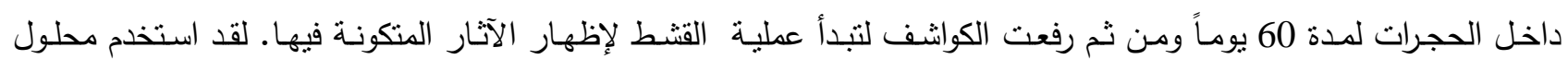
هيدروكسيد الصوديوم المائي NaOH بنقاوة 98\% وبدرجة حرارة

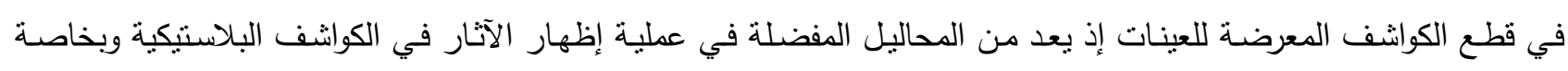

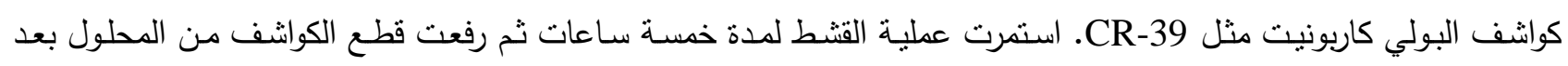

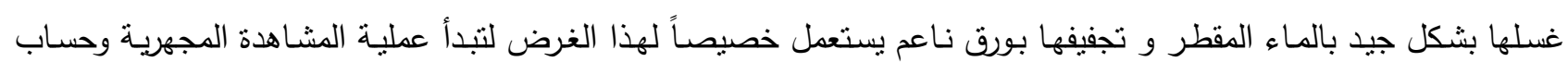

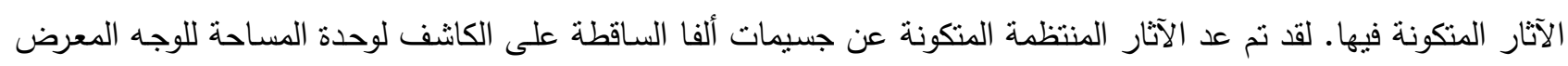

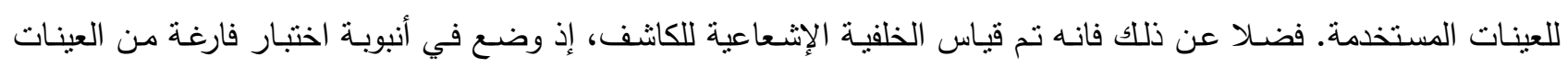
وأغلقت بإحكام بالطريقة نفسها وللمدة الزمنية التي حددت في حالة وجود العينات. وقد بلغت الخلفية الإشعاعية بحدود 499

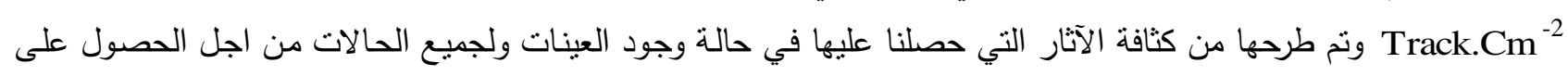
الكثافة الفعلية للآثار التابعة لجسيمات ألفا المنبعثة من العبنات قيد الدراسـة. وجرت عملية المشاهدة المجهرية باستخدام مجهر

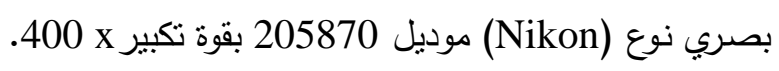


Al-) تم حساب تراكيز العناصر المشعة Ra

$$
C=\frac{\sum N-\sum B}{\varepsilon \cdot I . T \cdot W}
$$

.(Maqtary et al., 2008

إذ أن C تمثل تركيز العنصر المشع بوحدة (Bq/kg) و $N$ م المساحة الكلية تحت الذروة الضوئية ولطاقة العنصر المشع و B \الخفية الإثعاعية تحت الذروة الضوئية ولطاقة العنصر المشع.ع كفاءة الكاشف الوميضي ولطاقة العنصر المشع و I شدة

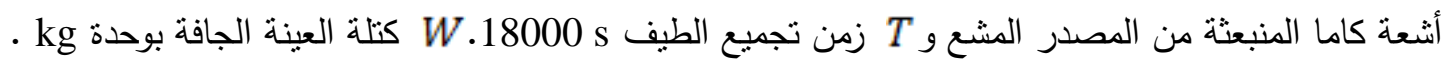
نم حساب معدل الجرعة الممتصة في الهواء وعلى ارتفاع متز واحد من سطح الارض بوحدات (بSv/h) باستخدام المعادلة النالية - (Mahur et al., 2008) $D\left(\mu \mathrm{Sv} \cdot \mathrm{h}^{-1}\right)=\left(0.462 \mathrm{C}_{\mathrm{Ra}}+0.604 \mathrm{C}_{\mathrm{Th}}+0.0417 \mathrm{C}_{\mathrm{K}}\right) * 0.001 * 0.7+C_{\mathrm{CO}}$

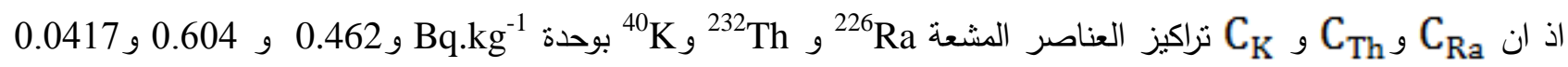
معاملات التحويل الخاصة بالعناصر أعلاه على التوالي بوحدة 0.7 Sv/Gy و nقعامل التحويل بين الجرعة الممتصة والجرعة المؤثرة. و COCO هو حد الأشعة الكونية المساهمة في الجرعة المدنصة في العينات والذي تم حسابه من برنامج

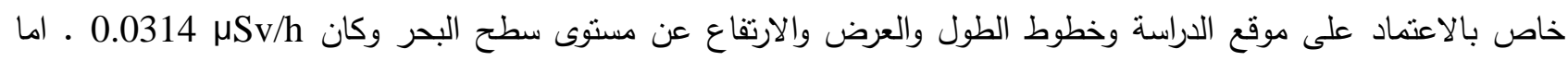
مؤشرات التلوث الإشعاعي للعناصر Ra

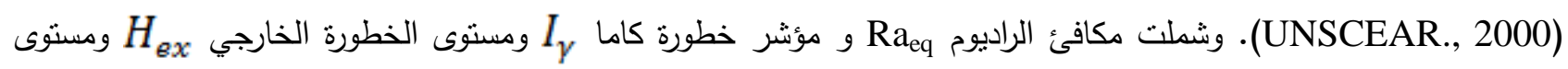
الخطورة الداخلي

$$
\begin{aligned}
& R a_{e q}=C_{\mathrm{Ra}}+1.43 \mathrm{C}_{\mathrm{Th}}+0.077 \mathrm{C}_{\mathrm{K}} \\
& I_{Y}=\frac{C_{\mathrm{Ra}}}{150}+\frac{\mathrm{C}_{\mathrm{Th}}}{100}+\frac{\mathrm{C}_{\mathrm{K}}}{1500} \\
& H_{e x}=\frac{C_{\mathrm{Ra}}}{370}+\frac{\mathrm{C}_{\mathrm{Th}}}{259}+\frac{\mathrm{C}_{\mathrm{K}}}{4810} \leq 1 \\
& H_{\text {in }}=\frac{C_{\mathrm{Ra}}}{185}+\frac{\mathrm{C}_{\mathrm{Th}}}{259}+\frac{\mathrm{C}_{\mathrm{K}}}{4810} \leq 1
\end{aligned}
$$

حسابات تقتية كاشف الأثر النووي (CR-39)

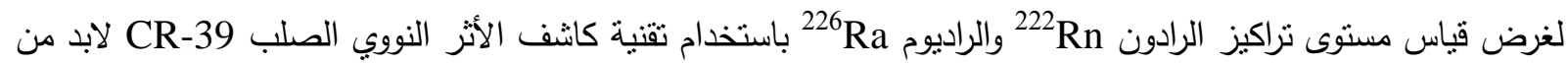
تحديد ثابت الانتشار K للمنظومة المستخدمة، إذ إن ثابت الانتشار يختلف من منظومة لأخرى إذ يعتمد على الأبعاد الهندسية لحجرة الانتشار (التشعيع). ولقد تم تحديد ثابت الانتشار K لحجرة الانتشار التي استخدمت في هذه الدراسة وفق العلاقة الآتية استتاداً إلى الأبعاد الهندسية لحجرة الانتشار (Barillon et al., 1991).

$$
K=\frac{1}{4} r\left(2 \cos \theta c-r / R_{\alpha}\right)
$$




$$
\text { صبا سالم محمد و هناء إحسان حسن }
$$

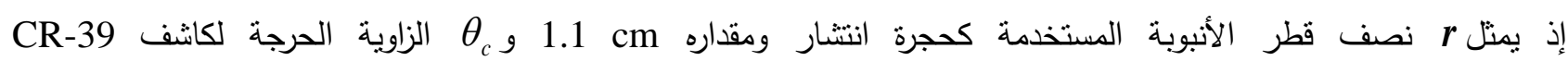

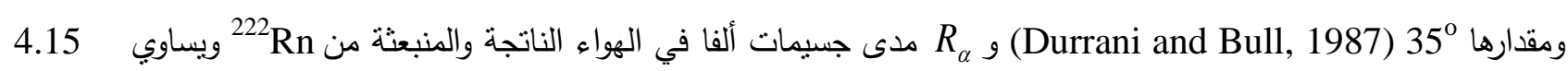

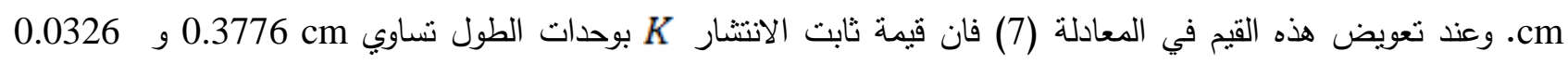
. Tr.cm ${ }^{-2} \cdot \mathrm{d}^{-1} / \mathrm{Bq} \cdot \mathrm{m}^{-3}$ يمكن حسـاب تركيـز الـرادون فـي الحيـز الهـوائي المحصـور بـين العينــة والكاثـف وذلــك باسـتخدام العلاقــة الآتيـة:

.(Azam et al, 1995)

$$
\rho=k \quad C_{\text {Rna }} \mathrm{T}
$$

إذ أن: Track/cm² ويمكن إيجاد تركيز الرادون في العينات باستخدام العلاقة الآتية (Al- Bataina et al., 1997):

$$
\mathrm{C}_{\text {Rns }}=\lambda_{\text {Rn }} \mathrm{C}_{\text {Rna }} \mathrm{h} \mathrm{T} / \mathrm{L}
$$

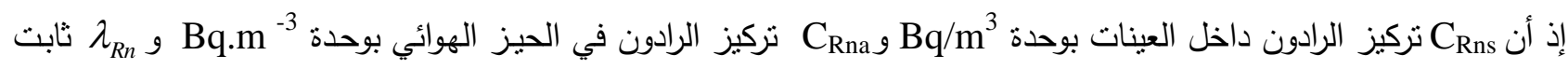

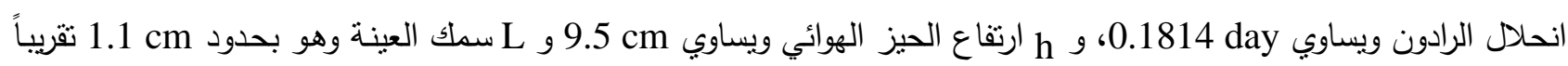
و ون النتعيع 60 يوماً. إن معدل التبخر السطحي هو عدد ذرات الرادون المغادرة من سطح المادة على وحدة المساحة السطحية على وحدة الزمن ويمكن

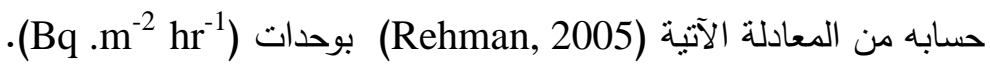

$$
\begin{aligned}
& \mathrm{E}_{\mathrm{R}}\left(\mathrm{Bq} \cdot \mathrm{m}^{-2} \cdot \mathrm{h}^{-1}\right)=\frac{\mathrm{C}_{\mathrm{Rn}}\left(\mathrm{C} \cdot \mathrm{a}+\lambda_{R n} \mathrm{~V}_{\mathrm{a}}\right)}{\mathrm{a}\left(1-\mathrm{e}^{-\left(\frac{\mathrm{C}_{\mathrm{a}} \mathrm{a}}{\mathrm{V}_{\mathrm{a}}}+\lambda_{\mathrm{Rn}}\right)}\right) \mathrm{T} .24}
\end{aligned}
$$

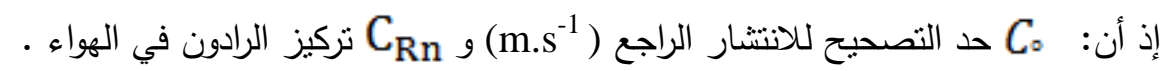

$\mathrm{C}_{o}=\lambda_{\mathrm{Rn}} L$

$$
\begin{aligned}
& \text { a المساحة السطحية للعينة (m²). }
\end{aligned}
$$

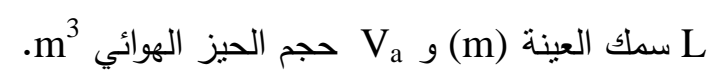$$
V_{\mathrm{a}}=\pi \mathrm{r}^{2}
$$

وهناك معادلة أخرى لحساب معدل التبخر السطحي (Nain et al., 2006)

$$
\mathrm{E}_{\mathrm{N}}\left(\mathrm{Bq} \cdot \mathrm{m}^{-2} \cdot \mathrm{h}^{-1}\right)=\frac{\mathrm{G}_{\mathrm{Rn}} \mathrm{T} \cdot 24 \mathrm{v}_{\mathrm{a}} \lambda_{R n}}{\mathrm{a} \cdot 24\left(\mathrm{~T}+1 / \lambda_{\mathrm{Rn}}\left(\mathrm{e}^{\left.\left.-\lambda_{\mathrm{Rn}} \mathrm{T}^{\mathrm{T}}-1\right)\right)}\right.\right.}
$$

وإن محتوى الراديوم الفعال C بوحدات Bq.kg من العلاقة الآتية (Rehman, 2005): 


$$
C_{\text {RaR }}=\frac{E_{R}}{\rho_{s} \lambda_{\text {Rn. }} E L}
$$

$$
\rho_{\mathrm{s}}=\mathrm{W}_{\mathrm{s}} / \mathrm{V}_{\mathrm{s}} \text { إذ إذ }
$$

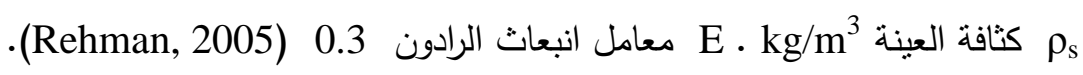
W كتلة العينة. $\mathrm{E}_{\mathrm{R}}$

\section{النتائج والمناقشة}

يبين الجدول (1) أرقام العينات وكتلها وتراكيز العناصر المشعة Ra

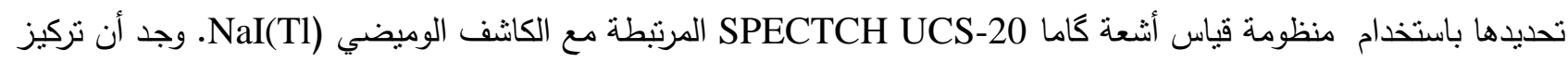

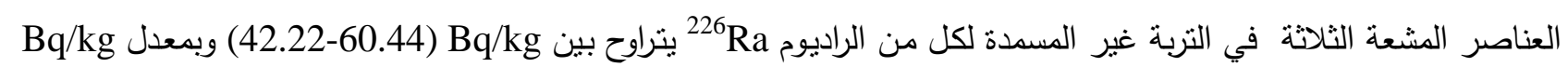

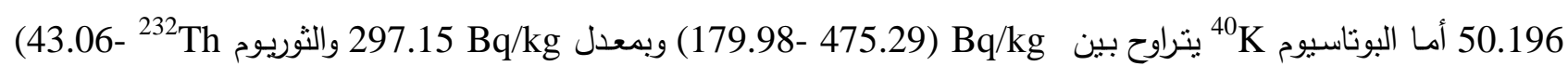

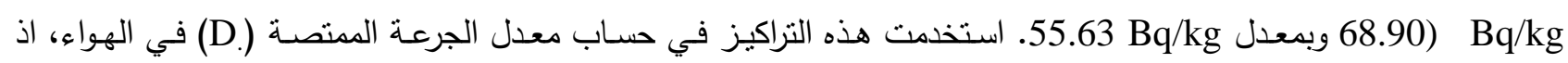

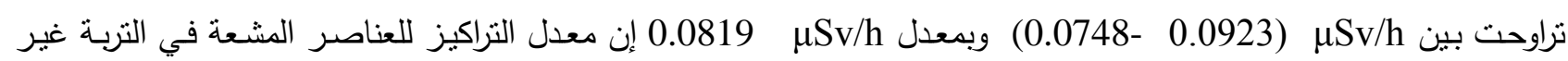
المسمدة و الجرعة الممنصة ل التكل خطورة لأنها تقع ضمن القيم المسموح بها عالميا (UNSCEAR, 2000) وكما موضحة

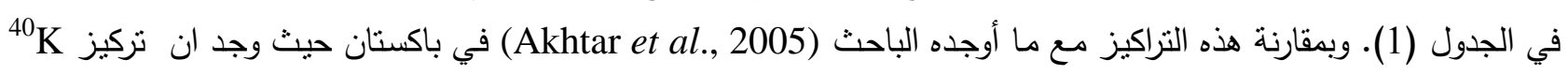

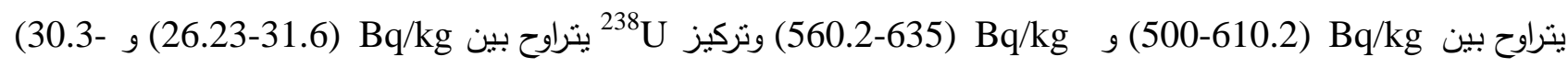

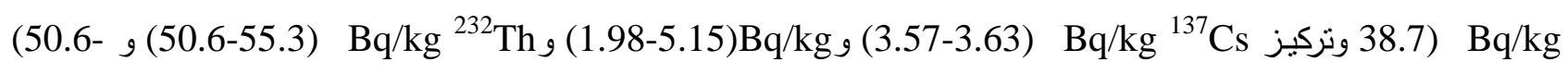
and Boucenna, 2011) Bq/kg من خلال دراسة في الجزائر تراكيز العناصر المشعة الراديوم Roukhenfouf

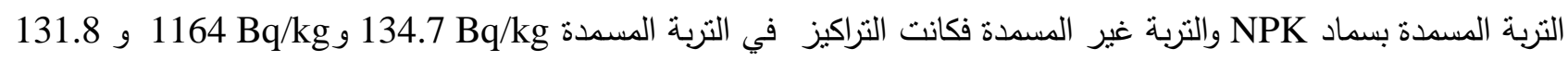

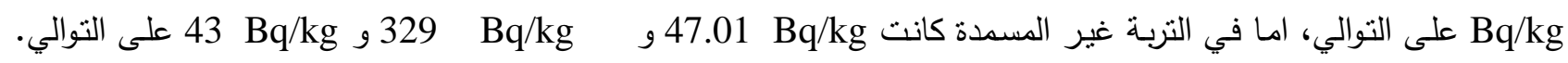

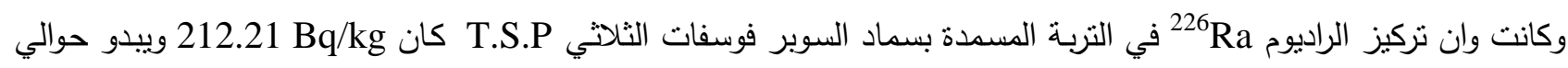
أربعة أضعاف تركيزه في التربة غير المسمدة وان نسبة الفرق بين التركيز حوال 76\% وهذا يدل على إن سماد السوبر فوسفات

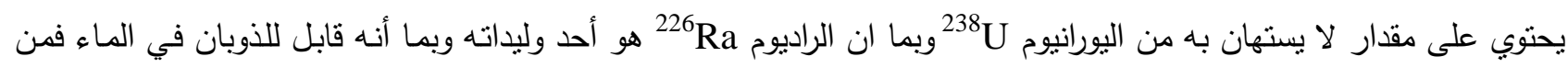

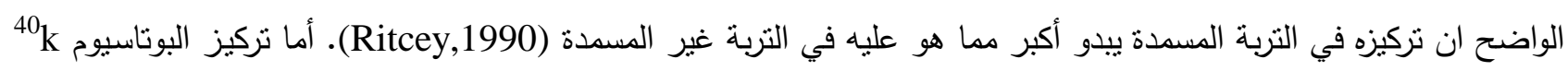
فقد كان 620.33 Bq/kg وقد أرتفع بشكل واضح في التربة المسمدة بسماد NPK وذللك لاحتواء السماد على نسبة من البوتاسيوم

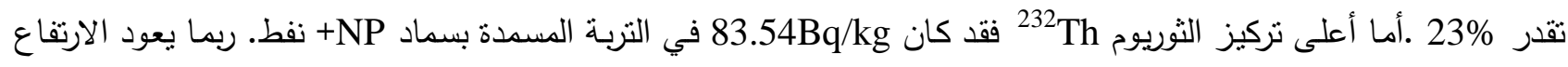
لاحتواء السماد على نسبة من النفط ومن المعروف ان النفط يحتوي على نسب غير قليلة من العناصر المشعة (IAEA, 2001).

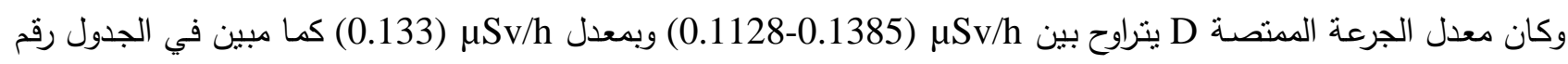
(1). والثكل (1) و(2) يبين علاقة تراكيز العناصر المشعة قيد الدراسة للتربة غير المسمدة والتربة المسمدة في العينات المدروسـة 
الجدول 1: أرقام وأسماء العينـات وكتلها وتراكيز كل من الرديوم Ra

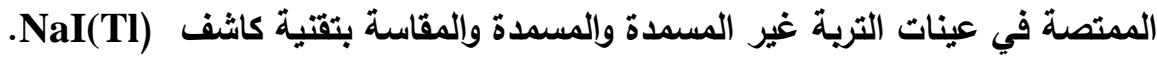

\begin{tabular}{|c|c|c|c|c|c|c|}
\hline \multirow{2}{*}{ ألعينات } & \multirow{2}{*}{ أسماء العينات } & \multirow{2}{*}{ الكتلة } & \multicolumn{3}{|c|}{ تراكيز العناصر المشعة } & \multirow{2}{*}{ 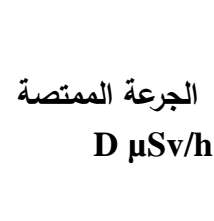 } \\
\hline & & & ${ }^{226} \mathrm{Ra}$ & ${ }^{40} \mathrm{~K}$ & ${ }^{232} \mathrm{Th}$ & \\
\hline \multicolumn{7}{|c|}{ الترية غير المسمدة } \\
\hline 1 & تربة غير مسمدة موقع 1 & 250.0 & 47.22 & 475.29 & 68.90 & 2370.09 \\
\hline 2 & تربة غير مسمدة موقع 2 & 250.0 & 50.27 & 248.57 & 68.90 & 0.08674 \\
\hline 3 & تربة غير مسددة موقع 3 & 250.0 & 50.81 & 272.16 & 43.06 & 0.07668 \\
\hline 4 & تربة غير مسمدة موقع 4 & 250.0 & 42.22 & 309.73 & 49.09 & 0.07485 \\
\hline 5 & تربة غير مسمدة موقع 5 & 250.0 & 60.444 & 179.98 & 48.23 & 0.07929 \\
\hline \multicolumn{3}{|c|}{ Average \pm STD } & $50.196 \pm 6.66$ & $297.15 \pm 11.02$ & $55.63 \pm 12.32$ & $0.0819 \pm 0.007$ \\
\hline \multicolumn{3}{|c|}{ (UNSCEAR, 2000) } & $17-60$ & $140-850$ & $11-64$ & 0.1314 \\
\hline \multicolumn{7}{|c|}{ الترية المسمدة } \\
\hline 6 & $\begin{array}{c}\text { NPK تربة مسمدة بسماد } \\
\text { عراقي }\end{array}$ & 250.0 & 131.41 & 620.33 & 72.35 & 590.122 \\
\hline 7 & تربة مسمدة بسمادMAPعراقي & 250.0 & 111.10 & 479.23 & 68.04 & 0.1128 \\
\hline 8 & $\begin{array}{c}\text { TSP تربة مسمدة بسماد } \\
\text { عراقي }\end{array}$ & 250.0 & 212.21 & 345.55 & 60.28 & 13830. \\
\hline 9 & 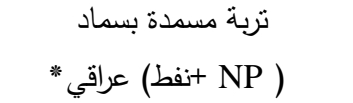 & 250.0 & 190.63 & 350.35 & 5483. & 3850.1 \\
\hline 10 & 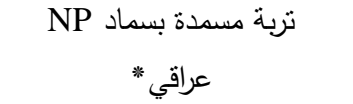 & 250.0 & 173.98 & 364.33 & 63.73 & 0.1279 \\
\hline \multicolumn{3}{|c|}{ Average \pm STD } & $163.9 \pm 41.8$ & $412.7 \pm 83.0$ & $80.0 \pm 31.6$ & $20.133 \pm 0.0$ \\
\hline
\end{tabular}

*NPK سماد (بوتاسيوم ، فسفور ، نيتروجين)

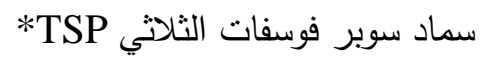

*MAP سماد فوسفات الأمونيوم الأحادية عنسية

* NP سماد (فسفور ، نيتروجين) 


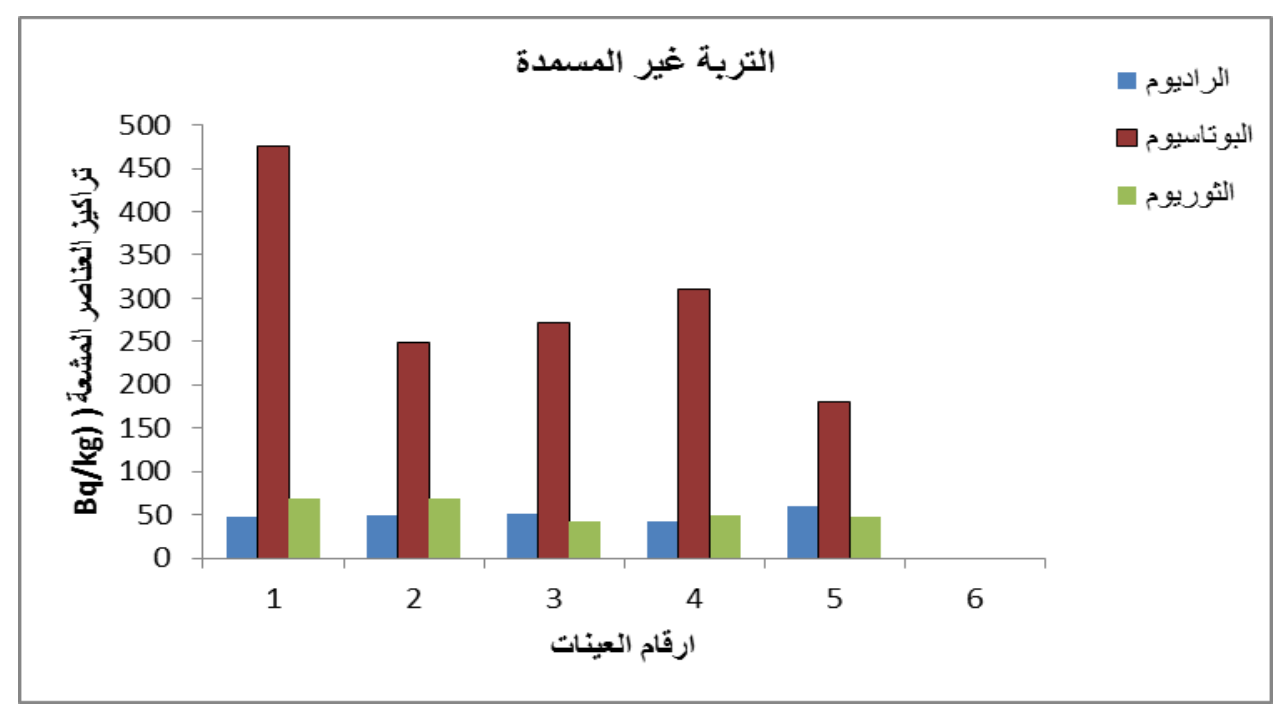

الثكل 1: تراكيز العناصر المشعة في الترية غير المسمدة ولمواقع مختلفة

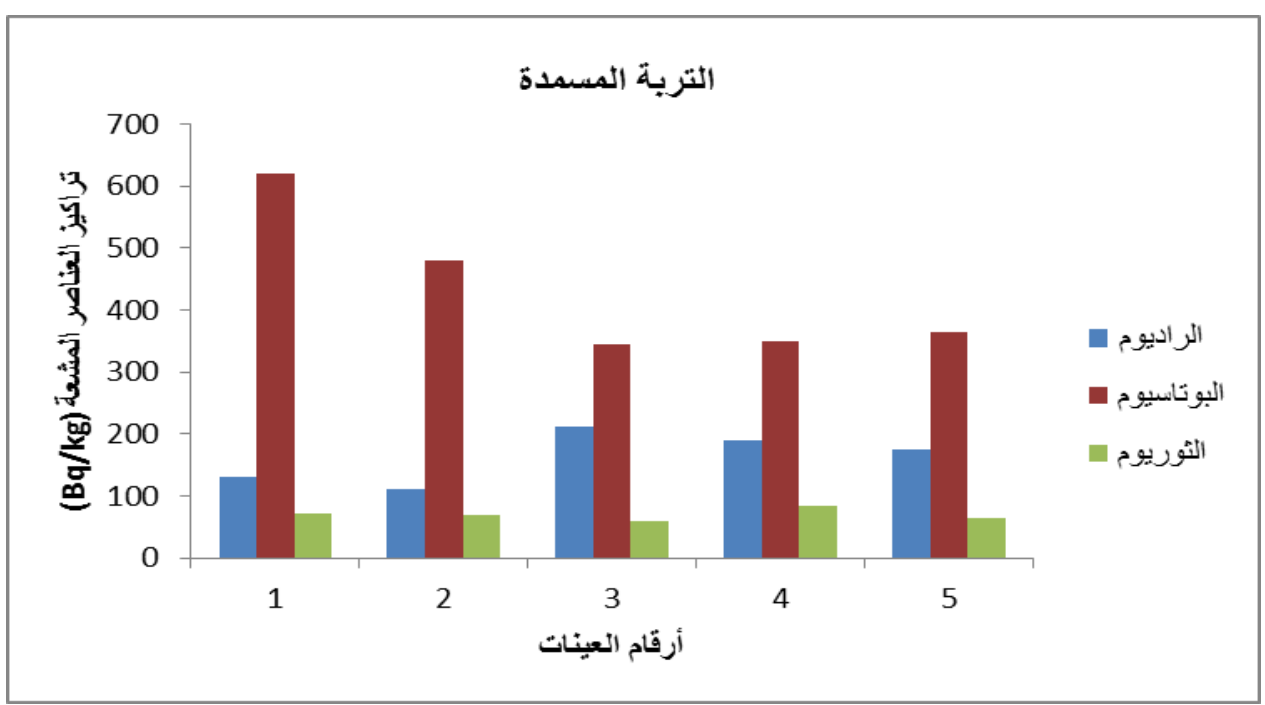

الشكل 2: تراكيز العناصر المشعة في التربة المسمدة ويأنواع مختلفة من الأسمدة

يبين الجدول (2) مقارنة بين قيم مكافئ الراديوم Raeq ودليل كاما I ومستوى الخطورة الخارجي Hex ومستوى الخطورة الداخلي

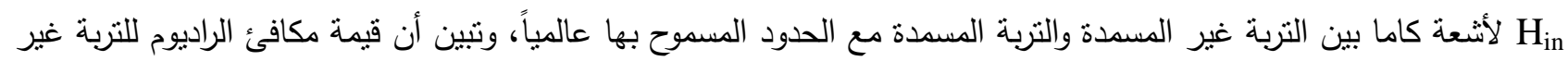

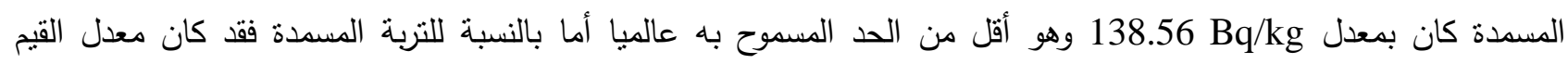

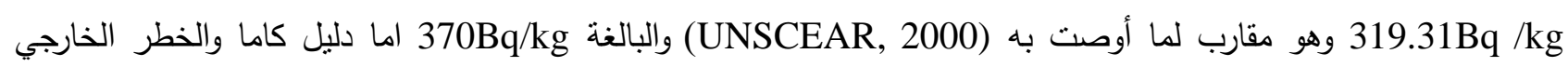
والداخلي فان قيمهم في التربة غير المسمدة أقل من واحد ماعدا في العينة رقم 1 فقد كان دليل كاما 1.32 وربما يعود السبب الى الى

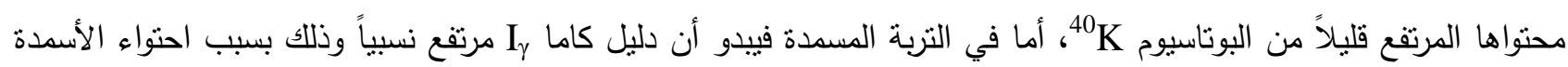

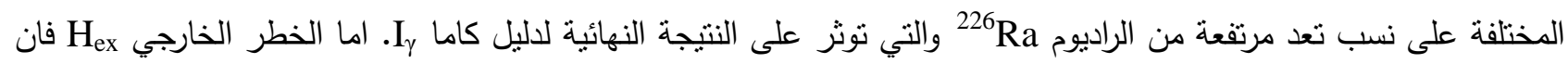

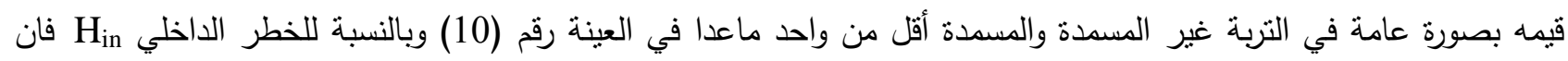
قيمه في عينات التربة غير المسمدة أقل من واحد ومن الواضح ان قيمه في التربة المسمدة تجاوزت الواحد وكانت بمعدل 1.326 وهذا يعني ان الأسمدة قد أضافت نسبة غير قليلة من العناصر المشعة وخاصة اليورانيوم و وليداته وكذلك البوتاسيوم 


$$
\text { صبا سالم محمد و هناء إحسان حسن }
$$

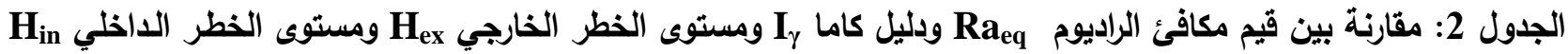
لأثنعة كاما في عينات التربة غير المسمدة والمسمدة

\begin{tabular}{|c|c|c|c|c|}
\hline أرقام العينات & $\begin{array}{c}\text { مكافئ الراديوم } \\
\text { Ra }_{\text {eq }}(\mathrm{Bq} / \mathrm{kg})\end{array}$ & $\begin{array}{l}\text { دليل كاما } \\
\text { I }_{Y}\end{array}$ & الخطر الخارجي & $\begin{array}{c}\text { الخطر الاخلي } \\
\text { Hin }_{\text {in }}\end{array}$ \\
\hline \multicolumn{5}{|c|}{ التربة غير المسمدة } \\
\hline 1 & 182.35 & 1.3207 & 0.9246 & 0.6200 \\
\hline 2 & 167.94 & 1.1899 & 0.4535 & 0.5894 \\
\hline 3 & 133.35 & 0.9528 & 0.3601 & 0.4975 \\
\hline 4 & 136.27 & 0.9788 & 0.3680 & 0.4821 \\
\hline 5 & 143.28 & 1.0053 & 0.3870 & 0.55038 \\
\hline Average \pm STD & \pm 0.331138 .56 & $0.987 \pm 0.242$ & $0.374 \pm 0.0891$ & $0.488 \pm 0.112$ \\
\hline \multicolumn{5}{|c|}{ التربة المسمدة } \\
\hline 6 & 282.63 & 2.0131 & 0.7634 & 1.118 \\
\hline 7 & 283.52 & 42.00 & 0.7659 & 21.17 \\
\hline 8 & 325.03 & 2.248 & 0.8782 & 1.452 \\
\hline 9 & 293.18 & 2.040 & 0.7921 & 1.2623 \\
\hline 10 & 412.20 & 2.8652 & 1.1135 & 1.6287 \\
\hline Average \pm STD & $319.31 \pm 54.70$ & $2.23 \pm 0.366$ & $0.862 \pm 0.147$ & $1.326 \pm 0.211$ \\
\hline $\begin{array}{c}\text { Worldwide } \\
\text { Limited }\end{array}$ & 370 & $\leq 1$ & $\leq 1$ & $\leq 1$ \\
\hline
\end{tabular}

الجدول (3) يوضح نتائج تقنية كاثف الأثر النووي CR-39 ومن الواضح قيمة تراكيز غاز الرادون في الهواء العينة (3.027-

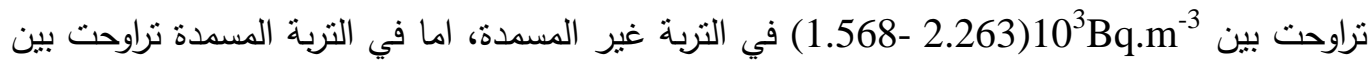

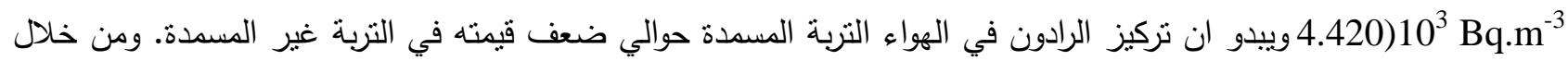

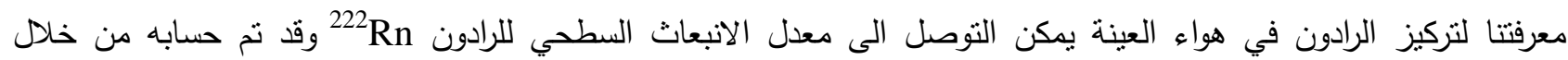
معادلتين للباحثين (Rehman, 2005)، (Nain et al., 2006) من العلاقتين 10 و 13 ، تبدو قيم التبخر السطحي بصورة

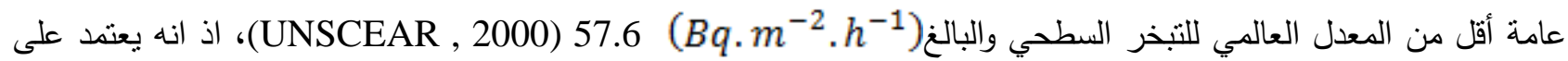
مقدار ما ينبخر من سطح العينة فقط وحيث ان معدل النسب بين E و E E في التربة الغير مسمدة هو 1.005 وفي التربة

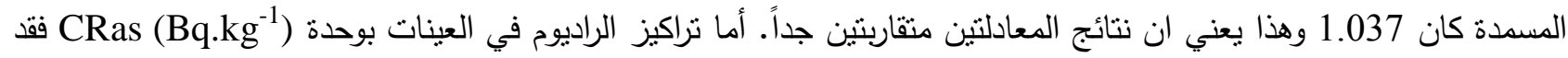
تم حسابه باستخدام المعادلات (10،8) وكانت اعلى قيمة لتراكيز الراديوم في عينات التربة غير المسمدة تعود الى العينة 5 بينما أعلى قيمة لتركيز الراديوم في عينات التربة المسمدة تعود إلى العينة 8 (تربة مسمدة بسماد TSP). وبمقارنة نتائج تركيز الراديوم لترائ

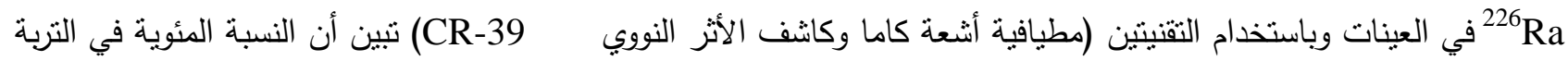




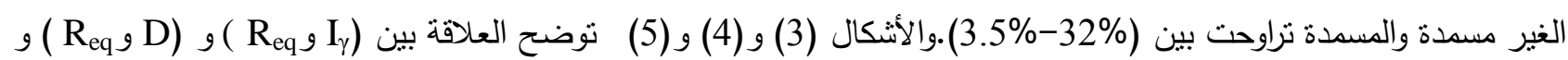
( R R $\mathrm{CH}_{\mathrm{eq}}$ )

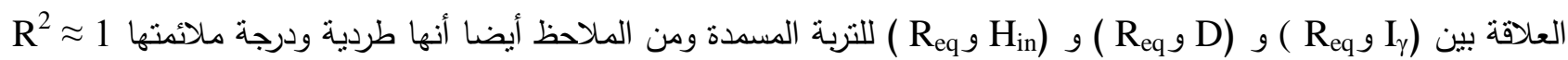
وهذا يعني ان مؤشرات التلوث بصورة عامة أساسها تراكيز العناصر المشعة ضمن العلاقات وان أي منها ممكن أن يعطي فكرة واضحة عن التلوث الإثعاعي إذ ما زادت قيمتها عن القيم المسموح بها.

الجدول 3: ارقام العينات وكثافة الاثار م) CRas(Bq/kg) وتركيز الراديوم في العينات

\begin{tabular}{|c|c|c|c|c|c|c|}
\hline \multirow{2}{*}{$\begin{array}{l}\text { Sample } \\
\text { No. }\end{array}$} & \multirow{2}{*}{$\rho\left(\operatorname{Tr} / \mathrm{cm}^{2}\right)$} & \multirow{2}{*}{$\begin{array}{c}\text { تركيز الرادون } \\
\text { في الهواء }{ }^{222} \mathbf{R n} \\
\mathbf{C}_{\mathrm{Rna}} \\
\text { Bq.m }{ }^{-3} \\
\text { x10 } \\
\end{array}$} & \multicolumn{2}{|c|}{$\begin{array}{c}\text { Radon Surface Exhalation Rate } \mathbf{E} \\
.\left(\mathrm{Bq} \cdot \mathrm{m}^{-2} \cdot \mathrm{h}^{-1}\right)\end{array}$} & \multirow{2}{*}{$\mathbf{E}_{\mathrm{R}} / \mathbf{E}_{\mathrm{N}}$} & \multirow{2}{*}{$\begin{array}{c}\text { CRas } \\
(\text { Eq. 10) }\end{array}$} \\
\hline & & & $\begin{array}{c}E_{N} \\
(\text { Eq. 13) }\end{array}$ & $\begin{array}{c}\mathbf{E}_{\mathrm{R}} \\
(\mathbf{E q} .10)\end{array}$ & & \\
\hline \multicolumn{7}{|c|}{ التربة غير المسمدة } \\
\hline 1 & 3067 & 1.568 & 1.239 & 1.244 & 1.003 & 41.702 \\
\hline 2 & 3697 & 1.890 & 1.494 & 1.500 & 1.003 & 50.269 \\
\hline 3 & 3604 & 1.842 & 1.456 & 1.462 & 1.003 & 49.004 \\
\hline 4 & 3399 & 1.640 & 1.297 & 1.302 & 1.003 & 43.636 \\
\hline 5 & 4501 & 2.263 & 1.786 & 1.813 & 1.015 & 60.771 \\
\hline \multicolumn{7}{|c|}{ التربة المسمدة } \\
\hline 6 & 6612 & 3.380 & 2.672 & 2.836 & 1.061 & 95.041 \\
\hline 7 & 5921 & 3.027 & 2.393 & 2.425 & 1.013 & 81.275 \\
\hline 8 & 8647 & 4.420 & 3.495 & 3.708 & 1.061 & 124.29 \\
\hline 9 & 8106 & 4.144 & 3.276 & 3.508 & 1.070 & 117.57 \\
\hline 10 & 8393 & 4.290 & 3.392 & 3.567 & 1.051 & 119.55 \\
\hline \multicolumn{7}{|c|}{ World Average Exhalation Rate $=57.6\left(B q \cdot \mathrm{m}^{-2} \cdot \mathrm{h}^{-1}\right)($ UNSCEAR ,2000) } \\
\hline
\end{tabular}

\section{الاستنتاجات}

1- إن الأسمدة من الممكن إن تكون احد أسباب التلوث الإشعاعي البيئي وقد تمنل خطورة على صحة الإنسان في حال تتاوله

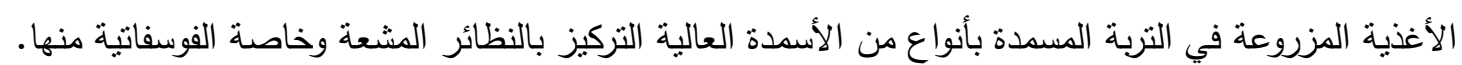

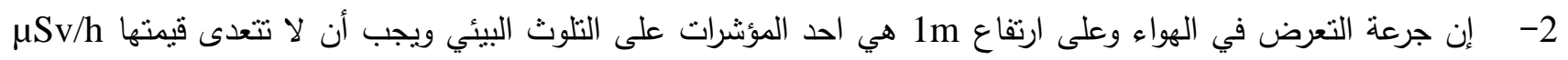

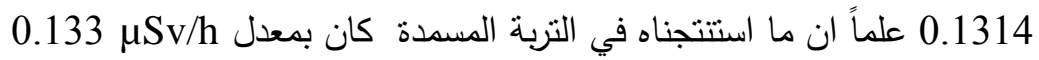
3- تم التوصل إلى أن معدل مكافئ الراديوم في التربة المسمدة يعادل تقريباً ضعف ما أوجدناه في التربة غير المسمدة وهذه

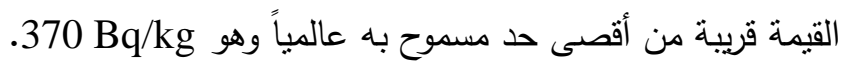

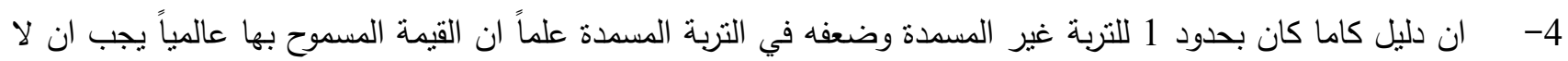
تتعدى الواحد. 


$$
\text { صبا سالم محمد و هناء إحسان حسن }
$$

5- ان الخطر الخارجي والداخلي في التربة غير المسمدة بصورة عامة اقل من واحد وان الخطر الداخلي في التربة المسمدة أكبر من واحد. 6- ينصح بتوخي الحذر عند استخدام الأسمدة الفوسفاتية وخاصة العالية التركيز بالفوسفات منل T.S.P. لأنها تحتوي على كمية لا بستهان بها من اليورانيوم ووليداته.

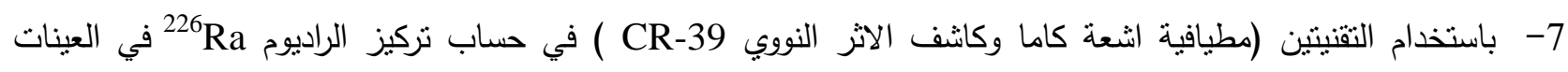
وبمقارنة نتائج التقنيتين تبين ان النسبة المئوية تراوحت بين (32\%-3.5 (3.5).

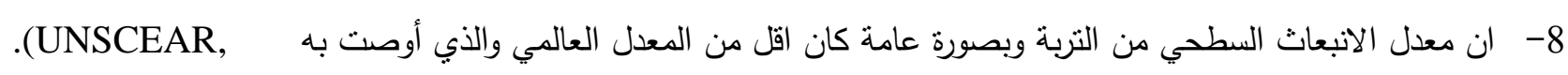
2000)

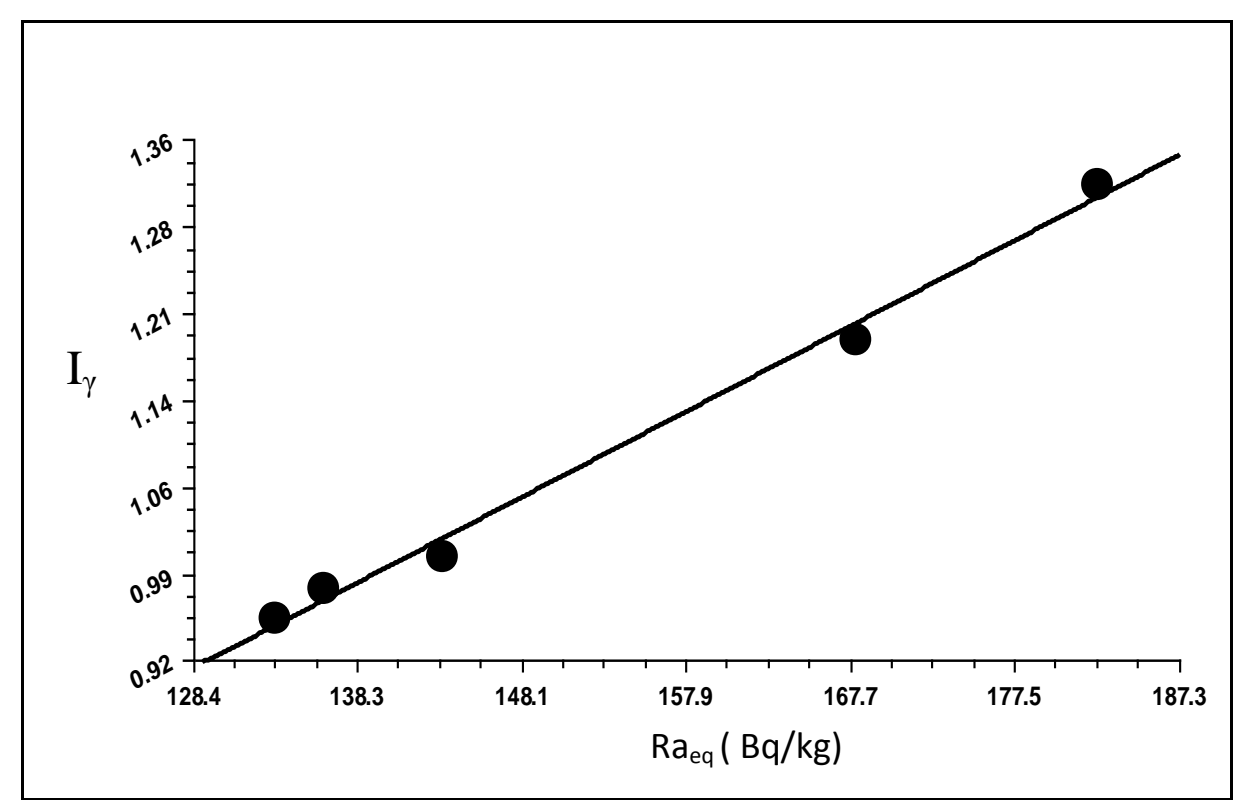

الثكل 3: علاقة مكافئ الراديوم مع دليل كاما للتربة غير المسمدة

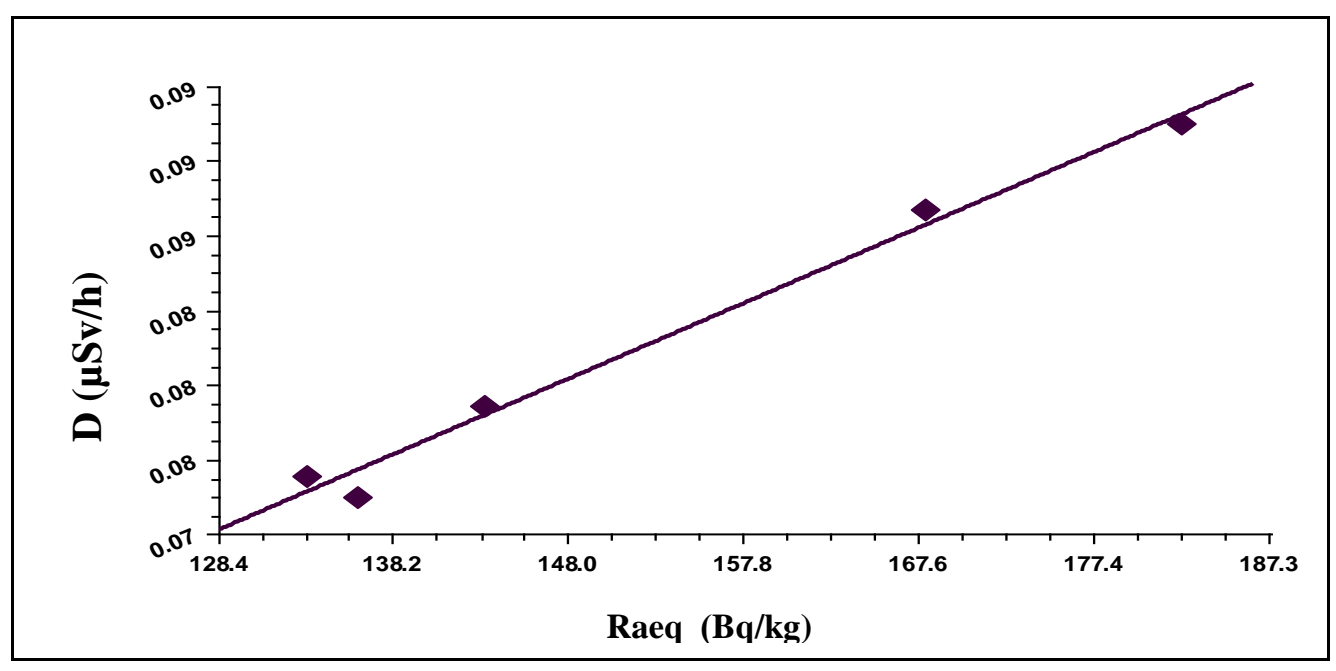

الثكل 4 : علاقة مكافئ الراديوم مع جرعة التعرض للترية غير المسمدة 


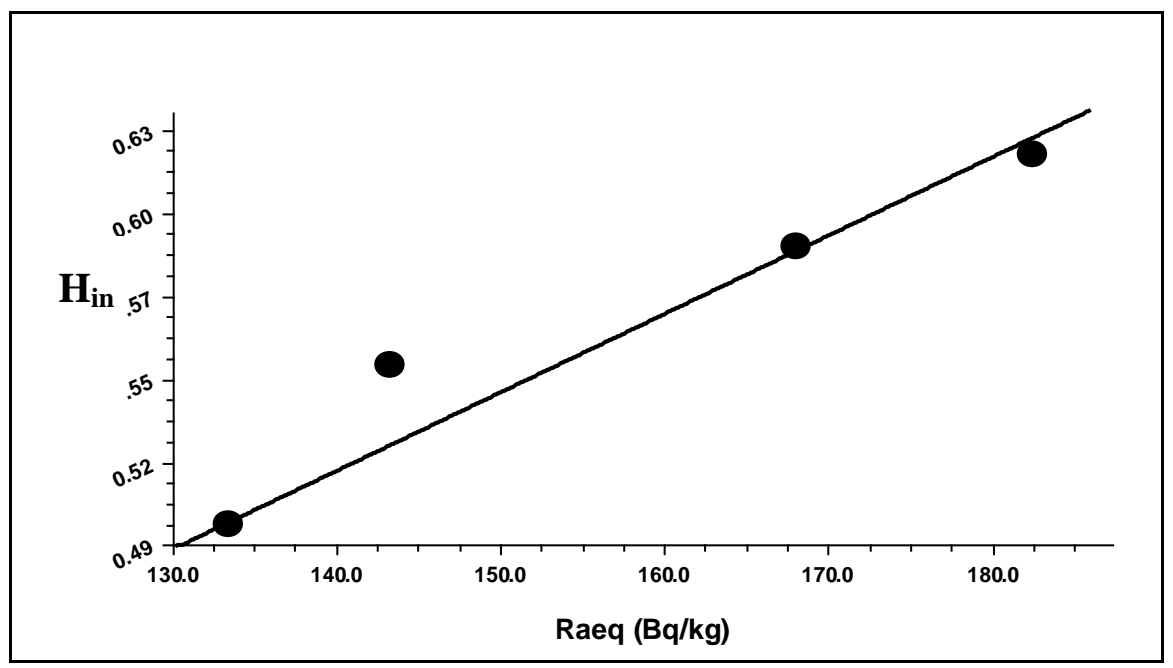

الثكل 5: علاقة مكافئ الراديوم مع التعرض الداخلي للتربة غير المسمدة

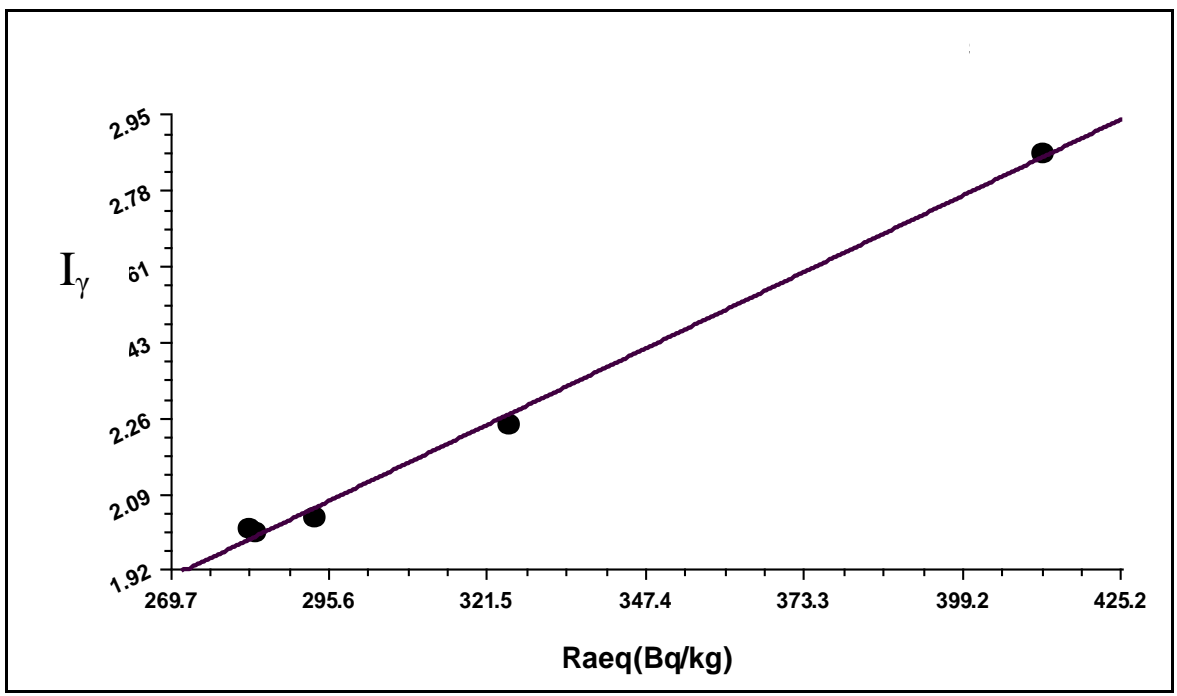

الثكل 6: علاقة مكافئ الراديوم مع دليل كاما للتربة المسمدة

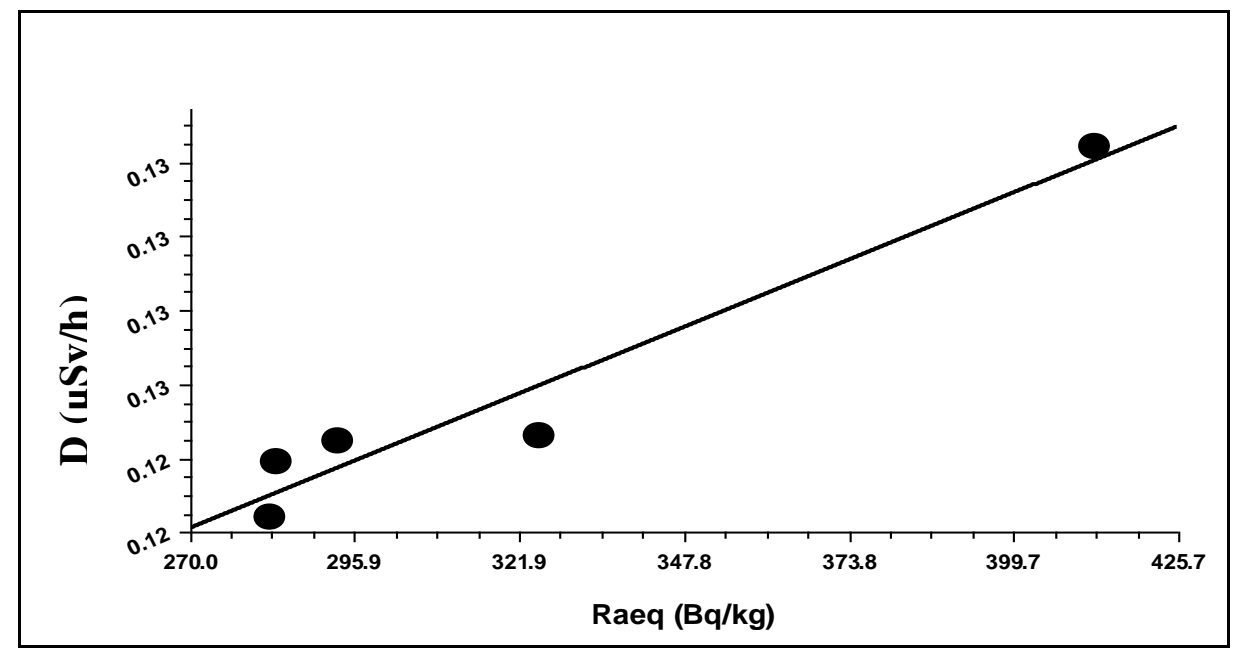

الثكل 7: علاقة مكافئ الراديوم مع جرعة التعرض للتربة المسمدة 


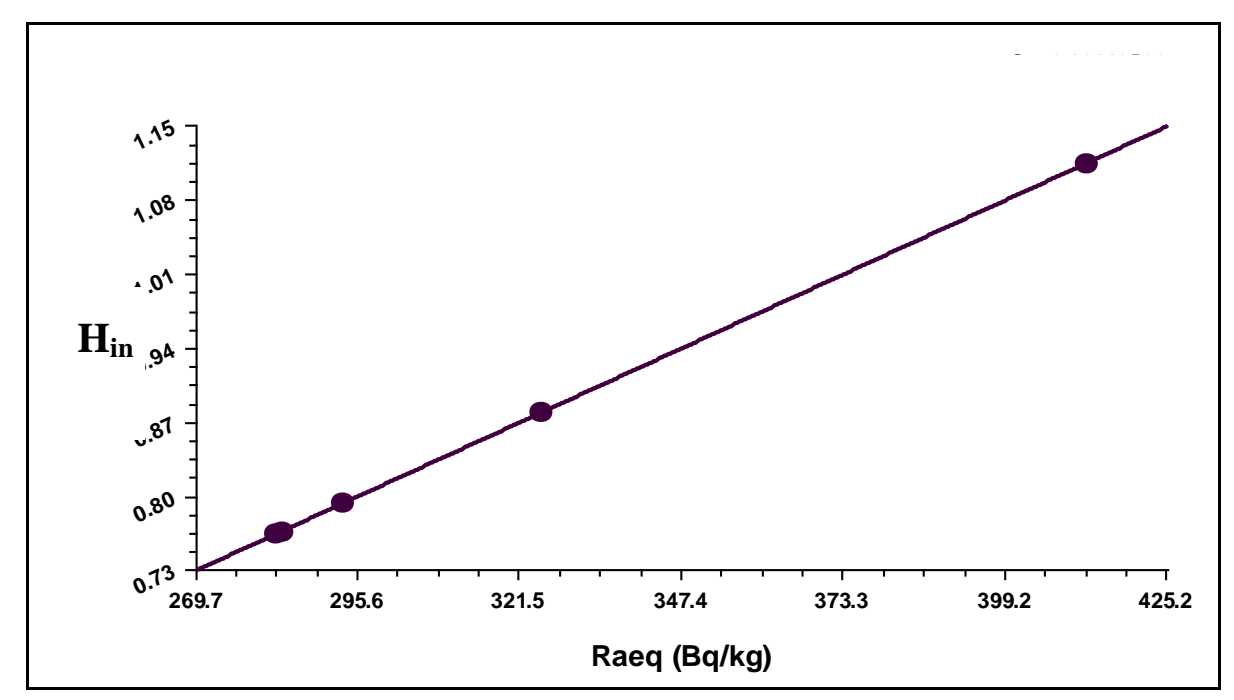

الشكل 8: علاقة مكافئ الراديوم مع التعرض الداخلي للتربة المسمدة

\section{المصادر العربية}

الصبحة، ليث أحمد (2001). نطبيق تقنية نووية في دراسة الأسمدة النباتية، مجلة علوم الرافدين. 12(3)، 87-92. سلامه، محمد عبد الرحمن (1994). مراقبة وقياس العناصر الشعُة في التربة. المركز القومي للأمان والرقابة الإشعاعية، هيئة

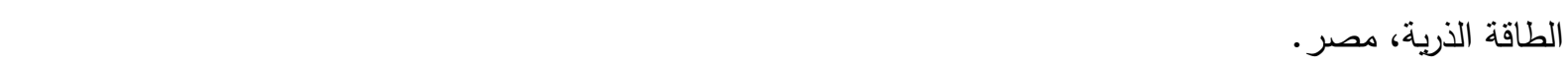

علي، عامر حسن ؛ محيميد، أحمد خلف؛ حسن، هناء إحسان (2013). تحديد مستوى الخلفية الإشعاعية في حرم جامعة الموصل باستخدام تقانات متعددة. بحث مقبول للنشر في مجلة علوم الرافدين، كلية العلوم، جامعة الموصل.

\section{المصادر الأجنبية}

Akhtar, N.; Tufail, M.; Ashraf M.; Mohsin, M.I. (2005). Measurement of environmental radioactivity for estimation of radiation exposure from saline soil of Lahor, Pakistan. Radiation Measurements, 39, 11-14.

Al-Bassam, K. (2007). Uranium in the Iraqi Phosphorites. Iraqi Bulletin of Geology and Mining, 3(2), 13-31.

AL-Bataina, B.A.; Ismail, A.M.; Kullab, M.K.; Abumurad, K.M.; Mustafa, H. (1997). Radon Measurements in Different Types of Natural Waters in Jordan. Radiat. Meas., 28,(1-6), 591594.

Al-Maqtary, K.; Murshid, M.; Bazohair, A.; Al-Zuhairy, M. (2008). Determination of radio nuclides for some local foodstuffs in republic of Yemen by using gamma rays spectral analysis technique. Abhath AL-Yarmook: Basic. Sci. and Eng., 17(IC), 415-423.

Al-Saif, A.S. (2009). Radiological aspects of hail region behavior of some radionuclides in soil. M.Sc. Thesis, College of Science, King Saud University.

Azam, A.; Naqui, A.; Srivatava, D. (1995). Radium concentration and Radon exhalation measurement using LR-115 Type II plastic track detectors. Nucl. Geophs, 9(6) 653-657.

Barillon, R.; Klein D.; Chambaudet, A.; Membrey, F.; Fromm, M. (1991). Additional uses of polymeric nuclear track detectors CR-39 and LR-115 for measuring radon emanation. Nucl. Tracks Radiat. Meas., 19, 291-295.

Boukhenfouf, W.; Boucenna, A. (2011). The radioactivity measurement in soil and fertilizers using gamma spectrometry technique. J. Environmental Radioactivity, 102, 336-339.

Calhan, P.; Chauhan, R.P.; Gupta, M. (2013). Estimation of naturally occurring radionuclides in fertilizers using gamma spectrometry and elemental analysis by XRF and XRD techniques,. Microchemical J., 106, 73-78. 
Catherin, T.M. (1965). "Fertilizer Application, Soil, Plant, Animal". London, Crosby.

Durrani, S.A.; Bull, R.K. (1987). "Solid State Nuclear Track Detection". Pergamon Press. Oxford.

Guimond, R.J.; Hardin, J.M. (1989). Radioactivity Released from phosphate containing fertilizers and from gypsum. Radiat. Phys. Chem. 34(2), 309-315.

International Basic Safety Standards IAEA, Safety Series 115 - I (2001). ICRP publication 60. Ann. IRCP. 21, 1-3, (1991).

Kadi, M.W.; Al-Eryani, D.A. (2012). Natural Radioactivity and radon exhalation in phosphate fertilizers. Arab. J. Sci. Eng., 37, 225-231.

Kant, K.; Upadhyay, S.B.; Sankawde, R.G.; Cchakarvarti, S.K. (2006). Radiologyical Risk Assessment of Use of Phosphate Fertilizers in soil. Iran. J. Radiat. Res., 4(2), 63-70.

Mahur, A.K.; Kumer, R.; Sonkawade, R.G.; Sengupta, D.; Prasad, R. (2008). Measurements of natural radioactivity and radon exhalation rate from rock samples of Jaduguda uranium mines and its radiological implications. Nucl. Inst. and Meth. in Phy. Res. B, 266, 15911597.

Nain, M.; Chauhan, R.P.; Chakarvarti, S.K. (2006). Alpha radioactivity in Indian cement samples. Iran J. Radiat. Res., 3(4), 171-176.

Rehman, S.U. (2005). Radon measurements with CR-39 detectors - implications for uranium ore analysis and risk assessment. Ph.D. Thesis, (PIEAS) Pakistan.

Ritcey, G.M. (1990). Weathering processes in uranium tailings and the migration of contaminants Internation atomic energy agency (IAEA). Envir. Beh. Rad. (310), 27-72.

Saad, A.F.; Abdullah, Y.K.; Hussein, N.A.; El -Yseery, I.S. (2010). Radon exhalation rate from building materials used on the Garyounis University campus, Benghazi, Libya. Turkish J. Eng. Env. Sci., 34, 67-74.

United Nations Scientific Committee on the Effects of Atomic Radiation (UNSCEAR), (2000). Sources and effects of ionizing radiation. Report to the General Assembly. New York, United Nation. 